\title{
Pengaruh Kompensasi dan Motivasi Terhadap Kinerja Avition Security dalam Pengamanan Bandar Udara Abdulrachman Saleh Malang
}

\author{
Dewi Ratna Sari \\ Elly Pujiastuti
}

\author{
Politeknik Penerbangan Surabaya \\ Jl. Jemur Andayani I/73 Surabaya
}

\begin{abstract}
Abstrak
Keberhasilan Bandar Udara Abdulrachmad Saleh Malang sangat dipengaruhi oleh kinerja karyawan/pegawai salah satunya Aviation Security (avsec) yang bertugas mence gah terjadi kejadian yang berbahaya. Bandar udara akan berusaha untuk meningkatkan kinerja pe gawainya agar tujuan bandar udara tercapai. Salah satu faktor yang dapat meningkatkan kinerja avsec adalah pemberian kompensasi danmotivasi. Penelitian ini bertujuan untuk mengetahui dan menganalisis pengaruh kompensasi danmotivasi kerja terhadap kinerja. Teknik pengambilan sampel menggunakan total sampling sehingga sampel penelitian ini adalah semua avsec yang berjumlah 50 orang. $k$. Teknik analisis data meng gunakan analisis regresi linier berganda dengan pengujian hipotesis menggunakan uji t. Hasil pengujian menunjukkan bahwa kompensasi berpengaruh positifdan signifikan terhadap kinerja avsec, hal ini dibuktikan dengan nilai koefisien regresi yang positif yaitu sebesar 0,145 dan nilai signifikasi uji $t$ yang lebih kecil dari 0,05 yaitu sebesar 0,004.Motivasi berpengaruh positif dan signifikan terhadap kinerjaavsec, hal ini dibuktikan dengannilai koefisien regresi yang positif yaitu sebesar 0, 555 dan nilai signifikasi uji tyang lebih kecil dari0,05 yaitu sebesar 0,002.
\end{abstract}

Kata-Kata Kunci : kompensasi, motivasi, kinerja karyawan (avsec).

\section{PENDAHULUAN}

\section{Pengaruh Kompensasi terhadap Kinerja karyawan}

Kompensasi menurut Hasibuan (2012:118) adalah semua pendapatan yang berbentuk uang, barang langsung atau tidak langsung yang diterima avsec sebagai imbalan atas jasa yang diberikan kepada perusahaan. Kompensasi sangat penting bagi karyawan, karena karyawan berharap dengan kompensasi yang diterimanya dapat memenuhi kebutuhannyadan mampu meningkatkan kesejahteraan hidupnya. Apabila suatu perusahaan dalammemberikan kompensasi kepada karyawan sudah dapat menimbulkan semangat dankegairahan kerja, maka salah satu tujuan perusahaan untuk meningkatkan produktivitasakan terpenuhi. Perusahaan biasanya merancang dan mengadministrasikan kompensasikaryawan. Bila kompensasi diberikan secara benar, para karyawan akan lebih terpuaskandan termotivasi untuk mencapai tujuan perusahaan. Oleh karena itu, bila para karyawan memandang kompensasinya tidak memadai, prestasi kerja, motivasi dan kepuasan kerjanyaakan turun.

Dari uraian di atas, maka hipotesis yang diajukan dalam penelitian ini adalah "Kompensasi berpengaruh positif dan signifikan terhadap kinerja avsec pada Bandar udara Abdulrachman Saleh Malang".

\section{Pengaruh Motivasi Kerja terhadap Kinerja Avsec}

Motivasi menurut Sopiah (2008:170) adalah suatu keadaan di mana usaha dankemauan keras seseorang diarahkan kepada pencapaian hasil-hasil atau tujuan tertentu karyawan yang termotivasi akan bersifat energik dan bersemangat dalam mengerjakan tugas-tugas yang 
diberikan kepadanya, karena motivasi kerja dapatmendorong semangat kerja para karyawan agar mau bekerja keras dan memberikan semuakemampuan serta ketrampilan demi tercapainya tujuan perusahaan. Sebaliknya para karyawan yang memiliki motivasi yang rendah akan sering menampilkan rasa tidak nyaman dan tidak senang terhadap pekerjaannya. Akibatnya kinerja avsec menjadi buruk dantujuan perusahaan tidak akan tercapai. Motivasi kerja avsec penting karena denganmotivasi kerja avsec, diharapkan setiap individu avsec mau bekerja keras danantusias untuk mencapai kinerja yang tinggi.

Dari uraian di atas, maka hipotesis yang diajukan dalam penelitian ini adalah "Motivasi kerja berpengaruh positif dan signifikan terhadap kinerja avsec Bandar udara Abdulrachman Saleh Malang".

\section{METODE PENELITIAN}

\section{Teknik Pengambilan Sampel}

Populasi penelitian ini adalah avsec bandar udara Abdulrachman Saleh Malang yang berjumlah 50 orang. Mengingat jumlahpopulasi relatif sedikit yakni sebanyak 50 orang, makaavsec Bandar udara Abdulrachman Saleh Malang 50 orang diteliti semua. Cara pengambilan sampeldengan cara seperti tersebut di atas dinamakan teknik sampling jenuh atau teknik totalsampling. Hal tersebut sejalan dengan pendapat Sugiyono (2011:84) yang menyatakan tekniksampling jenuh/teknik total sampling adalah teknik penentuan sampel bila semua anggotapopulasi digunakan sebagai sampel.

\section{Variabel dan Definisi Operasional Variabel}

Variabel bebas dalam penelitian ini adalah kompensasi (KP) dan Moivasi (MT),sedangkan variabel terikatnya adalah kinerja karyawan (KK). Definisi operasional masing-masingvariabel penelitian dapat dijelaskan sebagai berikut:

\section{Kompensasi (KP)}

Kompensasi adalah balas jasa yang diterima avsec bandar udara Abdulrachman Saleh Malang atas pekerjaannya baik berupa uang maupun barang. Indikator kompensasi dalam penelitian ini mengacu padateori Alma (2010:220) yaitu kompensasi harus dapat memenuhi kebutuhan minimal, kompensasi harus dapat mengikat, kompensasi harus dapat memotivasi karyawan,kompensasi harus adil, dan kompensasi tidak boleh bersifat statis dan harus bervariasi

\section{Motivasi (MT)}

Motivasi adalah kondisi yang menggerakkan avsec bandar udara Abdulrachman Saleh Malangagar bekerja giatdan berkeinginan untuk mencapai hasil yang maksimal. Indikator motivasi dalam penelitianini mengacu pada teori Maslow yang dikutip oleh Siagian (2009:287) yaitu: kebutuhanfisiologikal, kebutuhan keamanan, kebutuhan sosial, kebutuhan prestise, dan kebutuhanaktualisasi diri.

\section{Kinerja karyawan (KK)}

Kinerja karyawan dalam penelitian ini adalah hasil kerja atau prestasi kerja avsec bandar udara Abdulrachman Saleh MalangIndikator kinerja karyawan yang digunakan dalam penelitian ini mengacu pada pendapat Nawawi (2006:67) yaitu kuantitas hasil kerja yang dicapai, kualitas hasil kerja yangdicapai, jangka waktu mencapai kinerja tersebut, kehadiran dan kegiatan selama 
hadir ditempat kerja, kemampuan bekerja samaDalam penelitian ini digunakan kuesioner untuk mengukur variabel dan penilaiannyamenggunakan skala likert dengan kriteria: sangat setuju (nilai skor 5), setuju (nilai skor 4)netral (nilai skor 3), tidak setuju (nilai skor 2), dan sangat tidak setuju (nilai skor 1).

Kuesioner kemudian diuji dengan uji validitas dan reliabilitas untuk mengetahui apakahinstrumen berupa kuesioner yang disebarkan layak untuk digunakan dalam penelitian.

Uji Validitas adalah suatu derajat ketepatan alat ukur penelitian tentang isi sebenarnyayang diukur. Analisis validitas item bertujuan untuk menguji apakah tiap butir pertanyaanbenar-benar telah sahih. Menurut Sugiyono (2011:134) bila koefisien korelasi sama dengan0,3 atau lebih (paling kecil 0,3), maka butir instrumen dinyatakan valid. Sedangkan ujireliabilitas ditentukan berdasarkan nilai alpha cronbach, apabila nilai alpha lebih besar dari 0,6maka dikatakan variabel tersebut reliabel atau dapat diandalkan (Sugiyono, 2011:136).

\section{Teknik Analisis}

\section{Regresi Linier Berganda}

Analisis regresi linier berganda digunakan untuk mengukur ada atau tidaknyapengaruh antara kompensasi dan motivasi sebagai variabel independent (bebas) terhadapkinerja karyawan sebagai variabel dependent (terikat). Rumus regresi linier bergandamenurut Sugiyono (2011:192) adalah sebagai berikut :

$\mathrm{KK}=\mathrm{a}+\mathrm{b} 1 \mathrm{KP}+\mathrm{b} 2 \mathrm{MT}$

Keterangan:

$\mathrm{KKa} b 1, \ldots \mathrm{b} 2$

$\mathrm{KP}$

MT

variabel terikat kinerja karyawan

konstanta

koefisien regresi variabel bebas 1 sampai 3

variabel bebas kompensasi

variabel bebas motivasi

\section{Uji Hipotesis}

Pengujian hipotesis dalam penelitian ini menggunakan uji $t$. Uji statistik $t$ padadasarnya menunjukkan seberapa jauh pengaruh satu variabel independen secara individualdalam menerangkan variasi variabel dependen. Kriteria pengujian uji $t$ menurut Ghozali(2013:98) adalah jika nilai probabilitas lebih kecil dari 0,05 maka model regresi dapat digunakanuntuk memprediksi pengaruh parsial variabel independen terhadap variabel dependen. Uji tdilakukan dalam penelitian ini untuk menguji pengaruh secara parsial antara kompensasi danmotivasi terhadap kinerja karyawan. Kriteria uji t dalam penelitian ini adalah:

1) Jika nilaiprobabilitas > 0,05, maka secara parsial kompensasi dan motivasi kerja tidak berpengaruhterhadap kinerja karyawan.

2) Jika nilai probabilitas $<0,05$, maka secara parsial kompensasidan motivasi kerja berpengaruh terhadap kinerja karyawan.

\section{ANALISIS DAN PEMBAHASAN}

Bandar udara Abdulrachman Saleh Malang terdapat 12 kali penerbangan komersial berjadwal setiap hari di mulai jam 07.00 WIB sampai dengan 16.30 WIB. Pesawat yang 
digunakan antara lain Aibus A 320, Boeing 737 seri 500, 800 NG, 900 ER dan ATR 72600 dengan pergerakan pesawat dan penumpang dari bulan Januari s/d Juli 2017 :

a) Pergerakan Pesawat Dan Penumpang Bulan Juli 2017

\begin{tabular}{|c|c|c|c|c|c|c|c|c|}
\hline \multicolumn{2}{|c|}{ Pesawat } & \multicolumn{3}{|c|}{ Penumpang } & \multicolumn{2}{c|}{ Bagasi (Kg) } & \multicolumn{2}{c|}{ Kargo (Kg) } \\
\hline Dtg & Brkt & Dtg & Brkt & Transit & Dtg & Brkt & Dtg & Brkt \\
\hline 379 & 380 & 45.580 & 53.700 & - & 322.631 & 446.507 & 120.212 & 40.253 \\
\hline
\end{tabular}

b) Pergerakan Pesawat Dan Penumpang Bulan Januari - Juli 2017

\begin{tabular}{|c|c|c|c|c|c|c|c|c|c|}
\hline \multirow{2}{*}{ Bulan } & \multicolumn{1}{|c|}{ Pesawat } & \multicolumn{3}{c|}{ Penumpang } & \multicolumn{2}{c|}{ Bagasi (Kg) } & \multicolumn{2}{c|}{ Kargo } \\
\cline { 2 - 10 } & Dtg & Brk & Dtg & B rk & Trans & Dtg & Brkt & Dtg & Brkt \\
\hline Januari & 316 & 316 & 40.522 & 45.131 & - & 268.219 & 345.740 & 137.123 & 35.044 \\
\hline Pebruari & 263 & 263 & 35.334 & 34.511 & - & 223.369 & 243.509 & 128.466 & 27.403 \\
\hline Maret & 301 & 301 & 41.388 & 42.684 & - & 241.829 & 315.891 & 128.832 & 39.981 \\
\hline April & 286 & 287 & 40.760 & 41.893 & - & 240.350 & 302.051 & 126.330 & 32.009 \\
\hline Mei & 302 & 302 & 41.822 & 44.096 & - & 242.525 & 311.067 & 129.147 & 34.770 \\
\hline Juni & 288 & 288 & 40.652 & 36.801 & - & 288.402 & 288.307 & 126.479 & 37.445 \\
\hline Juli & 379 & 380 & 45.580 & 53.700 & - & 322.631 & 446.507 & 120.212 & 40.253 \\
\hline Jumlah & 2.135 & 2.137 & 286.058 & 298.816 & - & 1.827 .325 & 2.253 .325 & 896.589 & 246.905 \\
\hline
\end{tabular}

Dengan meningkatnya pergerakan pesawat dan penumpang dan barang mempengaruhi kinerja avsec di Bandar Udara Abdulrachman Saleh Malang

\section{Uji Validitas}

Hasil uji validitasmasing-masing variabel dengan menggunakan program SPSS adalah:

Tabel 1

Uji Validitas

\begin{tabular}{|l|l|l|l|}
\hline Variabel Pernyataan & Corrected Item- & Total Correlation & Keterangan \\
\hline Kompensasi (KP) & KP1 & 0,4463 & Valid \\
& KP2 & 0,4987 & Valid \\
& KP3 & 0,3614 & Valid \\
& KP4 & 0,6512 & Valid \\
& KP5 & 0,6030 & Valid \\
\hline Motivasi (MT) & MT1 & 0,4308 & Valid \\
& MT2 & 0,4660 & Valid \\
& MT3 & 0,5324 & Valid \\
& MT4 & 0,4674 & Valid \\
& MT5 & 0,4166 & Valid \\
\hline Kinerja Karyawan (KK) & KK1 & 0,3712 & Valid \\
& KK2 & 0,4033 & Valid \\
& KK3 & 0,4166 & Valid \\
& KK4 & 0,4354 & Valid \\
& KK5 & 0,7039 & Valid \\
\hline
\end{tabular}

Sumber: Data primer diolah, 2017

Dari Tabel 1 dapat diketahui bahwa koefisien korelasi semua butir dengan skor total (corrected item-total correlation) di atas 0,3 sehingga semua butir instrumen/pernyataan dalamvariabel kompensasi (KP), motivasi kerja (MT), dan kinerja karyawan (KK) dinyatakan valid. 


\section{Analisis Regresi Linier Berganda}

Analisis regresi linier berganda digunakan untuk mengukur ada atau tidaknya pengaruh antara kompensasi dan motivasi sebagai variabel independent (bebas) terhadap kinerja karyawan sebagai variabel dependent (terikat). Dari hasil pengolahan data dengan menggunakan Program SPSS diperoleh hasil sebagai berikut:

\section{Tabel 2}

\section{Koefisien Regresi Linier Berganda Coefficienats}

\begin{tabular}{|l|l|l|l|l|l|l|}
\hline Model & & $\mathrm{B}$ & \multicolumn{2}{|l|}{$\begin{array}{l}\text { Unstandardized } \\
\text { Coefficients }\end{array}$} & \multicolumn{2}{l|}{$\begin{array}{l}\text { Standardized } \\
\text { Coefficients }\end{array}$} \\
\cline { 4 - 7 } & & & Std. Error & Beta & T & Sig \\
\hline 1 & (Constant) & 1,122 &, 255 & & 4,612 &, 002 \\
& KP &, 145 &, 046 &, 218 & 3,236 &, 004 \\
& MT &, 555 &, 062 &, 618 & 9,248 &, 002 \\
\hline
\end{tabular}

Sumber: Data primer diolah, 2017

Tabel 2 menunjukkan persamaan regresi yang dapat menjelaskan hubungan antaravariabel bebas kompensasi (KP) dan motivasi (MT) terhadap variabel terikat kinerjakaryawan (KK). Dari tabel di atas diperoleh model regresi linier berganda sebagai berikut:

$$
\mathrm{KK}=1,122+0,145 \mathrm{KP}+0,555 \mathrm{MT}
$$

Berdasarkan model regresi di atas dapat dijelaskan bahwa :

1. Nilai konstanta sebesar 1,122. Hal ini menunjukkan bahwa jika variabel kompensasi(KP) dan motivasi (MT) sama dengan nol, maka kinerja karyawan (KK) akan sebesar 1,122 satuan.

2. Nilai koefisien regresi kompensasi (KP) sebesar 0,145 dan bernilai positif. Hal inimenunjukkan terjadinya perubahan yang searah. Artinya jika kompensasi ditingkatkan,maka akan dapat meningkatkan kinerja karyawan dengan asumsi variabel motivasi(MT) konstan.

3. Nilai koefisien regresi motivasi (MT) sebesar 0,555 dan bernilai positif. Hal inimenunjukkan terjadinya perubahan yang searah. Artinya jika motivasi (MT)ditingkatkan, maka akan dapat meningkatkan kinerja karyawan (KK) dengan asumsi variabel kompensasi (KP) konstan.

Dari model regresi linier berganda di atas dapat diketahui adanya pengaruh antarakompensasi (KP) dan motivasi (MT) terhadap kinerja karyawan (KK) yang dilihat dari koefisien regresi $\neq 0$.

\section{Uji Hipotesis}

Pengujian hipotesis dalam penelitian ini menggunakan uji t. Uji statistik $t$ pada dasarnya menunjukkan seberapa jauh pengaruh satu variabel independen secara individual dalam menerangkan variasi variabel dependen. Kriteria pengujian uji t menurut Ghozali (2013:98) adalah jika nilai probabilitas lebih kecil dari 0,05 maka model regresi dapat digunakan untuk memprediksi pengaruh parsial variabel independen terhadap variabel dependen. Uji t dilakukan dalam penelitian ini untuk menguji pengaruh secara parsial antara kompensasi dan motivasi terhadap kinerja karyawan. Kriteria uji t dalam penelitian ini adalah: 
1) Jika nilaiprobabilitas > 0,05, maka secara parsial kompensasi dan motivasi kerja tidak berpengaruh terhadap kinerja karyawan.

2) Jika nilai probabilitas $<0,05$, maka secara parsial kompensasi dan motivasi kerja berpengaruh terhadap kinerja karyawan.

Dari Tabel 2, dapat diketahui bahwa:

1) Nilai signifikasi variabel kompensasi (KP) lebih kecil dari 0,05 yaitu 0,004 , hal ini menunjukkan bahwa kompensai berpengaruh signifikan terhadap kinerja karyawan.

2) Nilai signifikasi variabel motivasi (MT) lebih kecil dari 0,05 yaitu 0,002 , hal ini menunjukkan bahwa motivasi berpengaruh signifikan terhadap kinerja karyawan.

\section{KESIMPULAN}

Berdasarkan hasil penelitian dan pembahasan yang telah dilakukan, maka skesimpulan yang dapat diambil dari penelitian ini adalah:

1) Kompensasi berpengaruh positif dan signifikan terhadap kinerja avsec.

2) Motivasi berpengaruh positif dan signifikan terhadap kinerja avsec.

\section{DAFTAR PUSTAKA}

Abdullah, M. 2014. Manajemen dan Evaluasi Kinerja Karyawan. Penerbit Aswaja Pressindo.Yogyakarta.

Abrivianto, O., B. Swasta, dan H. N Utami. 2014. Pengaruh Motivasi Kerja Dan KomitmenOrganisasional Terhadap Kinerja Karyawan (Studi pada karyawan bagian HRD PT.

Arthawena Sakti Gemilang Malang). Jurnal Administrasi Bisnis. Vol. 7(2).

Alma, B. 2010. Pengantar Bisnis. Edisi Revisi. Cetakan Keempat belas. Penerbit Alfabeta.Bandung.

Ghozali, I. 2005. Aplikasi Analisis Multivariate Dengan Program SPSS. Penerbit Badan PenerbitUniversitas Diponegoro. Semarang. . 2013. Aplikasi Analisis Multivariate Dengan Program IBM SPSS 21 Update PLS

Regresi.

Badan Penerbit Universitas Diponegoro. Semarang

Handoko, T. H. 2011. Manajemen Personalia dan Sumberdaya Manusia. Edisi Kedua. CetakanKedelapan belas. BPFE. Yogyakarta.

Hasibuan, M.S.P. 2012. Manajemen Sumber Daya Manusia. Edisi Revisi. Penerbit Bumi Aksara.Jakarta.

Nawawi, H. 2006. Evaluasi dan Manajemen Kinerja Di Lingkungan Perusahaan dan Industri. 